\title{
ANALISIS ANGGARAN PENDIDIKAN DAN PELATIHAN BAGI PENINGKATAN PROFESIONALISME GURU DI KABUPATEN MAMUJU
}

\section{Taufiq*}

\begin{abstract}
The research conducted aims to obtain an overview of the education and training budget for improving the professionalism of teachers in Mamuju district, using a qualitative approach. The technique used in determining research informants is purposive sampling. The data collection was carried out with participatory observation techniques, semi-structured interviews and document review. The results of the study show that the education and training budget planning process for increasing the professionalism of teachers in Mamuju District is not yet fully ideal for implementing the five principles that are theoretically believed to be good budgeting principles in the public sector. There are many influential factors in the budget planning process, namely apparatus resources, planning documents (development and budgeting), nominative lists, budgets, and facilities (facilities and infrastructure). The education and training budget for increasing teacher professionalism in the government in the Mamuju district faces the following constraints: 1 . Limited resources; 2) participant mechanisms for education and training for improving teacher professionalism; and 3) communication and coordination of related parties that are still weak. To overcome these various obstacles, interested parties have made staff review efforts to the regents, improved budgets and organized education and training for improving teacher professionalism and increasing the intensity of communication and coordination with various relevant parties.
\end{abstract}

Keywords: Education Budget, Training, Teacher Professionalism

*) Widyaiswara Ahli Muda BPSDM Provinsi Sulawesi Barat

E-mail: taufiqpasca@gmail.com 


\section{PENDAHULUAN}

Reformasi yang di mulai pada tahun 1998 merambah ke segala lini kehidupan masyarakat, bangsa dan negara. Salah satu satu lini yang terkena imbas ialah keuangan sektor publik, baik pemerintah Pusat maupun pemerintah Daerah (PEMDA). Pada hakikatnya, reformasi dimaksud merupakan tuntunan publik untuk melakukan perbaikan di semua lini pemerintah, terutama pelayanan yang pemilihan bersentuhan langsung dengan masyarakat. Secara lebih spesifik, reformasi di sektor keuangan Publik berisi tuntunan masyarakat yang antara lain menghendaki adanya penghematan anggaran, penghapusan biaya-biaya yang tidak perlu, dan pelaksanaan tender atau lelang yang di lakukan atas dasar kompetisi yang sehat (Mardiasmo, 2004: 26)

Anggaran pemda, khususnya program yang diarahkan untuk meningkatkan kapasitas profesionalisme Sumber Daya Manusia (SDM) aparatur, dengan kegiatan yang dititikberatkan pada pendidikan dan pelatihan (DIKLAT) tenaga pendidik dan kependidikan, mestinya direncanakan dengan baik. Pemerintah Kabupaten (Pemkab) Mamuju menghadapi kondisi masalah keterbatasan atau kekurangan SDM Aparatur. Berdasarkan data BPS, Pegawai Negeri Sipil (PNS) Pemkab Mamuju pada tahun 2013 berjumlah 3.424 orang. Jumlah tersebut mengalami kenaikan menjadi 3.438 orang pada tahun 2014, berdasarkan data yang dirilis oleh Badan Kepegawaian Daerah (BKD) Kabupaten Mamuju. Dengan jumlah penduduk lebih kurang 119.171 jiwa sampai dengan tahun 2013 (proyeksi penduduk dari BPS Kabupaten Mamuju Tahun 2014), jumlah pegawai tersebut diniai masih kurang. Oleh karena itu, BKD melalui Bidang Pengadaan dan Pengembangan Pegawai pada tahun 2014 masih melakukan rekrutmen pegawai untuk mengatasi kekurangan secara kuantitas tersebut. Dari 74 Formasi yang tersedia, baik tenaga guru, kesehatan, maupun teknis, yang diterima dan lulus sebanyak 64 orang.Sedangkan ditinjau dari aspek kualitas, SDM Aparatur Pemkab Mamuju juga belum sesuai dengan kondisi ideal yang diharapkan. Indikasi yang menunjukkan kondisi tersebut, misalnya adanya ketidaksesuaian antara jabatan dengan kompetensi yang dipersyaratkan. Padahal kompetensi jabatan merupakan salah satu 
persyaratan yang harus dipenuhi seorang pegawai untuk diangkat dalam suatu jabatan struktural berdasarkan Peraturan Pemerintah (PP) Nomor 100 Tahun 2000 jo PP Nomor 13 Tahun 2002, selain syarat berstatus sebagai PNS, jenjang kepangkatan, kualifikasi dan tingkat pendidikan, prestasi kerja, serta kesehatan jasmani dan rohani. Dalam konteks pemenuhan kompetensi jabatan, Diklat Kepemimpinan (Diklatpim) diselenggarakan untuk memenuhi persyaratan kompetensi kepemimpinan aparatur pemerintah yang sesuai dengan jenjang jabatan. Selain itu juga memenuhi amanat PP Nomor 100 Tahun 2000, yaitu PNS yang diangkat dalam suatu jabatan wajib mengikuti dan lulus Diklatpim sesuai dengan tingkat jabatan strukturalnya selambat-lambatnya dua belas bulan atau setahun setelah yang bersangkutan dilantik. Dalam perkembangannya, PP Nomor 100 Tahun 2000 kemudian direvisi dengan PP Nomor 13 Tahun 2002. PP yang direvisi sudah tidak memberikan batasan waktu yang tegas bagi PNS yang menduduki jabatan struktural harus mengikuti dan lulus Diklatpim.

Data hasil pra - penelitian yang dilakukan penulis menunjukkan bahwa 55,4 persen lebih pejabat struktural di Lingkungan Pemkab Mamuju belum Diklatpim. Artinya, hanya 44,6 persen pejabat yang sudah mengikuti dan lulus Diklatpim Tingkat II, III, IV, dalam rangka pemenuhan persyaratan kompetensi kepemimpinan aparatur di berbagaitingkat jabatan (Eselson II, III, IV). Jadi, selain keterbatasan anggaran yang dapat dialokasikan untuk kegiatan Diklat fungsional, penelitian awal atau pra- penelitian yang dilakukan penulis mengindikasikan adanya permasalahan dalam proses perencanaan anggaran diklat tersebut. Hal dimaksud tampak dalam fenomenafenomena berikut:

1. Alokasi anggaran Diklatpim belum didasarkan atas kebutuhan riil Satuan Kerja Perangkat Daerah (SKPD) Pengguna Anggaran, yaitu BKD Kabupaten Mamuju.

2. Praktik pengalokasian anggaran seperti disampaikan para informan pra- penelitian menguatkan dugaan penulis bahwa anggaran Diklatpim belum disusun berdasarkan pendekatan kinrerja (performance budgeting). 
3. Proses perencanaan anggaran Diklatpim belum sepenuhnya mencerminkan prinsip tranparasi dan akuntabilitas.

4. Fenomena terakhir yang menunjukkan adanya masalah dalam proses perencanaan anggaran adalah indikasi ketidakefisienan dan tidak ketidakefektifan anggaran, karena tidak adanya pedoman yang bisa dijadikan panduan dalam penyusunan ataupun perencanaan anggaran.

Halim (Halim dan Damayanti, 2007: 24) mengemukakan bahwa manajemen atau pengelolaan keuangan daerah merupakan: "Keseluruhan kegiatan yang meliputi perencanaan, pelaksanaan, penatausahaan, pelaporan, pertanggungjawaban, dan pengawasan keuangan daerah". Keuangan daerah sebagaimana dimaksud Halim bukan hanya sesuatu yang bisa dinilai dengan uang, tetapi juga semua bentuk kekayaan lain yang dimiliki oleh daerah. Hal tersebut mengacu pada PP No. 58 Tahun 2005 yang menyatakan bahwa: "Keuangan Daerah adalah semua hak dan kewajiban daerah dalam rangka penyelenggaraan pemerintahan daerah yang dapat dinilai dengan uang termasuk didalamnya segala bentuk kekayaan yang berhubungan dengan hak dan kewajiban tersebut".

Ruang lingkup reformasi anggaran diungkapkan Mardiasmo (2004: 28) terjadi pada dua aspek berikut:

a. Perubahan struktur anggaran (budget structure reform), dan

b. Perubahan proses penyusunan APBD (budget process reform)

Sehingga dapat disimpulkan bahwa Manajemen keuangan daerah merupakan keseluruhan aktvitas pengelolaan keuangan daerah yang dilakukan Pemda, meliputi perencanaan, pelaksanaan, penatausahaan, pelaporan, pertanggungjawaban, dan pengawasan keuangan daerah. Seiring dengan terjadinya reformasi, berbagai aktivitas tersebut ikut mengalami perubahan. Salah satu perubahan mendasar adalah proses penyusunan APBD yang menerapkan sistem anggaran pendekatan kinerja (performance budgeting), menggantikan pendekatan tradisional (traditional budgeting).

1.Konsep Anggaran

Defenisi anggaran cukup banyak di kemukakan oleh para ahli, salah satunya Mardiasmo (2004: 118) yang mengungkapkan bahwa : “ Anggaran sebagai alat perecanaan kegiatan public yang dinyatakan 
dalam satuan moneter sekaligus berfungsi sebagai alat pengendalian, Dalam konteks keuangan daerah, Mardiasmo (2004: 103) menyatakan bahwa: "Anggaran daerah adalah rencana kerja pemerintah daerah dalam bentuk uang (rupiah) dalam satu periode tertentu (satu tahun) ".Defenisi anggaran yang dikemukakan Mardiasmo lebih menekankan anggaran sebagai alat perencanaan sekaligus alat pengendalian. Sedangkan McKinney (1986: 131) mengungkapkan bahwa anggaran sector public lebih kompleks dari sekedar dokumen perencanaan, tetapi juga menjadi dokumen ekonomis, politik, dan sosial. Hal tersebut sebagaimana tergambar dalam kutipan berikut: " $A$ budget is an economic, planning, political, and social document. It is a comprehensive financial work plan covering a specific period of time. The plan outlines the services and activities or projects to be provided and indicates the necessary expenditures and available resources in quantitative terms".

Anggaran diperlukan karena adanya kebutuhan dan keinginan masyarakat yang tak terbatas dan terus berkembang, sedangkan sumber daya yang ada terbatas. Dalam rangka mencapai tujuan atau sasaran yang diharapkan, Anggarini dan Puranto (2010: 106 - 107) mengemukakan lima prinsip penganggaran yang harus dipegang teguh oleh para pihak yang terkait dalam penyusunan anggaran. Kelima prinsip tersebut ialah sebagai berikut: Transparansi dan akuntabilitas anggaran, Disiplin anggaran, Keadilan anggaran, Efisiensi dan efektivitas anggaran, Disusun dengan pendekatan kinerja,

Berdasarkan uraian di atas, penulis menyimpulkan bahwa anggaran merupakan dokumen rencana kerja yang dinyatakan dalam satuan moneter untuk periode tertentu. Selain sebagai dokumen perencanaan, anggaran juga merupakan dokumen ekonomis, politik, dan sosial. Anggaran daerah (APBD) sendiri mempunyai arti dan fungsi penting bagi Pemda, dalam rangka pelaksanaan pembangunan dan peningkatan kesejahteraan masyarakat. Di tengah keterbatasan anggaran. Pemda dituntut membuat skala prioritas. Pemda juga harus mengimplemantasikan prinsip - prinsip penganggaran, agar tujuan atau sasaran yang ditetapkan tercapai.

2.Perencanaan Strategik 
Rue and Byars (2007: 139) mengemukakan bahwa perencanaan strategik ialah: "Analogous to top level long-range planning; cover a relatively long period; affect many parts of the organization ". Ditambahkan oleh Rue and Byars (2007: 139) bahwa:" strategic planning is done primarily by toplevel managers, while operational planning is done by managers at all levels of the organization". Pengertian Rue and Byars tersebut merujuk pada karakteristik perencanaan strategic itu sendiri. Jangka waktu suatu perencanaan dibagi Hasibuan (2004: 111) ke dalam: Rencana jangka panjang (long term planning), waktunya lebih dari lima tahun. Rencana jangka menengah (middle term planning), waktunya antara 2 sampai 5 tahun. Rencana jangka pendek (short term planning), waktunya antara 1 sampai 2 tahun.

Adapun tujuan perencanaan strategik (strategic planning), menurut Tripomo dan Udan (2005: 167) adalah: Menentukan arah organisasi (organization direction), strategy (strategi formulation) yang akan menciptakan competitive advantage bagi organisasi dan mengembangkan rencana untuk menjalankan strategi guna mencapai bayangan masa depan yang diinginkan ".

Rencana Kerja SKPD (Renja SKPD), Renja SKPD merupakan dokumen rencana pembangunan masing - masing SKPD yang berjangka waktu 1 (satu) tahun, memuat kebijakan, program, dan kegiatan yang disusun sesuai dengan tugas dan fungsi SKPD yang bersangkutan berdasarkan urusan yang menjadi kewenangan daerah, sasaran (indikator) hasil dan keluaran yang terukur, beserta rincian pendanaannya.

1. Perencanaan Anggaran

2. Pendidikan dan Pelatihan Kepemimpinan

\section{METODE PENELITIAN}

Penelitian yang dilakukan penulis menggunakan pendekatan kualitatif. Pendekatan tersebut melibatkan data berbentuk nonangka, yaitu berupa kalimat atau narasi, untuk kemudian diolah dan menghasilkan suatu temuan penelitian. Pemilihan pendekatan kualitatif didasarkan atas asumsi penulis bahwa permasalahan perencanaan anggaran Diklatpim pada Pemkab Mamuju belum jelas letak 
persoalannya. Keterbatasan anggaran memang diakui sebagai masalah utama, tetapi informasi mengenai hal tersebut masih perlu didalami untuk memahami makna permasalahan sebenarnya. Selain itu, penulis juga berasumsi bahwa perencanaan anggaran Diklatpim merupakan hal yang kompleks. Dimana dalam prosesnya melibatkan berbagai pihak yang berkepentingan. Bukan hanya BKD selaku Pengguna Anggaran, tetapi di dalamnya antara lain juga melibatkan Badan Perencanaan Pembangunan Daerah (BAPPEDA), Dinas Pendapatan, Pengelolaan Keuangan dan Aset Daerah (DPPKAD), inspektorat, dan pihak Legislatif (DPRD).

Informan penenlitian ditentukan secara purposive sampling,. Dalam penelitian penulis, pihak - pihak yang menjadi informan kunci berasal dari pihak eksekutif dan legislatif di lingkungan Pemkab Mamuju serta Lembaga Diklat Pemerintah Terakreditasi menyelenggarakan Diklatpim. Pihak eksekutif meliputi BKD (Kepala Badan, Kabid Diklat, Kasubid Diklat Struktural dan Tugas Belajar Aparatur dan Pelaksana Tugas Kasubag Program dan pelaporan), BAPPEDA (Kabid Perencanaan Makro dan Pengendalian), DPPKAD (Kasi Anggaran), dan Inspektorat (Auditor pada Inspektur Pembantu Wilayah II). Informan yang berasal dari pihak Legislatif adalah Wakil Ketua komisi I dan Anggota Badan Anggaran (Banggar) DPRD Kabupaten Mamuju. Sedangkan dari penyelenggara Diklatpim diwakili oleh Kabid Diklat Struktural dan Prajabatan Badan Pendidikan dan Pelatihan Daerah (BANDIKLATDA) Provinsi Kalimantan Selatan. Selain itu, penulis juga mewawancarai beberapa PNSD atau Pejabat Struktural di lingkungan Pemkab Mamuju yang menjadi kelompok sasaran kegiatan. Pemilihan kelompok sasaran kegiatan sebagai informan kunci dimaksudkan untuk memperoleh informasi mengenai perencanaan anggaran Diklatpim pada Pemkab dari perspektif pegawai atau pejabat yang sudah dan belum mengikuti diklat tersebut.

Teknik pengumpulan data dilakukan melalui observasi partisipatif, wawancara semiterstruktur, dan telah dokumen. Ketiga teknik tersebut dilengkapi dengan instrument masing - masing, berupa pedoman atau panduan pengumpulan data. Agar derajat keterpercayaan atau kredibilitas data penelitian terpenuhi, penulis menggunakan tiga 
diantara enam teknik yang dikemukakan oleh Sugiyono (2014: 122-129), yaitu peningkatan ketekunan, triangulasi, dan penggunaan bahan referensi. Sedangkan perosedur analisis data mengacu pada Model Interaktif Miles and Huberman (Sugiyono, 2014: 91) yang terdiri dari pengumpulan data (data collection), reduksi data (data reduction), penyajian data (data display), dan penarikan kesimpulan / verifikasi (conclusion drawing / verification).

\section{HASIL PENELITIAN}

Perencanaan anggaran Diklatpim pada Pemkab Mamuju pada prosesnya dapat dianalisis melalui lima prinsip penganggaran yang dikemukakan oleh Anggarini dan Puranto (2010: 106-107), yaitu transparansi dan akuntabilitas, disiplin, keadilan, efisiensi dan efektivitas, dan disusun berdasarkan pendekatan kinerja. Proses perencanaan anggaran Diklatpim sendiri dipengaruhi oleh berbagai faktor yang menjadi masukan (input), yaitu SDM aparatur, peraturan perundang undangan yang berlaku, dokumen perencanaan, daftar nominative, anggaran serta sarana dan prasarana yang tersedia.

Secara garis besar, anggaran Diklatpim yang dianggarkan Pemkab Mamuju melalui BKD terdiri atas anggaran yang terkait langsung dengan peserta diklat (kontribusi, penunjang kegiatan, dan perjalanan dinas peserta) dan anggaran pendukung kegiatan diklat (penggandaan dokumen dan perjalanan dinas pegawai BKD). Kondisi anggaran tersebut mengalami tren penurunan dalam tiga tahun terakhir periode Renstra Tahun 2011 s.d. 2015. Anggaran tersebut mengalami kenaikan kembali transisi dari Renstra Tahun 2011 - 2015 ke Renstra Tahun 2016 - 2020.

Faktor terakhir yang berpngaruh terhadap proses perencanaan anggaran Diklatpim adalah sarana dan prasarana. Hasil penelitian menunjukkan bahwa Pemkab Mamuju, khususnya BKD selaku Pengguna Anggaran, belum mempunyai fasilitas diklat yang representatif. Fasilitas yang dimiliki hanya mencukupi kebutuhan penyelesaian tugas administratif atau tata usaha (clerical work) kepegawaian. Sehingga, penyelenggaraan Diklatpim melalui pola fasilitas / Kemitraan belum memungkinkan untuk dilaksanakan di Kabupaten Mamuju. Oleh karena itu, PNSD atau Pejabat Struktural di Lingkungan Pemkab Mamuju 
diikutkan Diklatpim melalui pola Penyertaan pada lembaga diklat pemerintah yang terakreditasi menyelenggarakan Diklatpim Tingkat II

a. Transparansi dan Akuntabilitas Anggaran

b. Disiplin Anggaran

c. Efisiensi dan Efektivitas Anggaran

d. Disusun Berdasarkan Pendekatan Kinerja

Dengan dipengaruhi oleh berbagai faktor dan prinsip - prinsip perencanaan anggaran yang belum sepenuhnya diimplementasikan secara ideal, maka keluaran (output) berupa anggaran Diklatpim yang sesuai dengan kebutuhan SKPD Pengguna Anggaran belum tercapai. Indikasinya adalah target kinerja Diklat Struktural (Diklatpim) dalam Renstra SKPD BKD Kabupaten Mamuju Tahun 2011-2015 yang hanya tercapai 53,37 persen pada akhir tahun 2015. Selain itu, capaian target Diklat Struktural (Diklatpim) dalam RPJMD Kabupaten Mamuju Tahun 2011- 2015 hanya 43,10 persen. Pencapaian target perencanaan jangka menengah tersebut masih jauh dari target yang ditetapkan sebesar 98 persen pada akhir tahun 2015.

Anggaran Diklatpim pada Pemkab Mamuju yang bsesuai dengan kebutuhan SKPD Pengguna Anggaran belum tercapai, disebabkan adanya permasalahan atau kendala- kendala yang dihadapi perencanaan Anggaran Diklat tersebut, yaitu: Keterbatasan anggaran menjadi penyebab utama masih banyaknya PNSD atau Pejabat Struktural di lingkungan Pemkab Mamuju yang belum Diklatpim. Kondisi tersebut ditambah dengan pengalokasian anggaran yang belum sepenuhnya sesuai dengan kebutuhan dan peningkatan kapasitas SDM Aparatur Pemda belum ditempatkan sebagai prioritas utama pembangunan daerah. Di samping, penyelenggaraan Diklatpim dengan pola Fasilitas/ Kemitraan belum bisa dilaksanakan, karena kekurangan SDM yang memenuhi kualifikasi untuk menyelenggarakan Diklatpim dan belum tersedianya fasilitas Diklat representatif yang dimiliki Pemkab Mamuju, khususnya BKD selaku pembina dan pelaksana di bidang kediklatan.

Mekanisme pengiriman peserta yang didasarkan pada kuota dan pemanggilan oleh Lembaga Diklat Pemerintah Terakreditasi juga menjadi salah satu kendala yang menyebabkan belum efektifnya Anggaran Diklatpim pada Pemkab Mamuju. Selain itu, kuota yang ditentukan oleh 
lembaga duklat tersebut belum tentu terealisasi seratus persen atau sesuai perencanaan. Mekanisme pencalonan dan penentuan peserta Diklatim oleh TSPDI juga dinilai masih kurang transparan dan akuntabel.

Lemahnya komunikasi dan koordinasi di antara pihak- pihak berkepentingan dalam perencanaan anggaran Diklatpim merupakan kendala lain yang dihadapi BKD Kabupaten Mamuju selaku Pengguna Anggaran. Kendala tersebut terlihat dari perubahan regulasi yang cukup dinamis tapi tidak dibarengi efektivitas diseminasi informasi kedaerah, perencanaan anggaran dengan koordinasi di antara pihak- pihak internal dan eksternal yang kurang baik, serta pelaksanaan kegiatan diklat melalui pemberitahuan dan pemanggilan peserta yang terkesan mendadak. Kondisi tersebut turut menjadi penyebab belum optimalnya anggaran Diklatpim yang direncanakan.

\section{SIMPULAN}

Berdasarkan hasil penelitian dan pembahasan tentang perencanaan anggaran Diklatpim pada Pemkab Mamuju, dapat dibuat simpulan sebagai berikut:

1. Pemkab Mamuju melalui BKD belum mengimplementasikan prinsipprinsip penganggaran secara ideal dalam perencanaan anggaran Diklatpim. Akan tetapi, harus diakui bahwa pihak- pihak terkait telah berupaya untuk menerapkan prinsip- prinsip yang terdiri dari transparansi dan akuntabilitas, disiplin, keadilan, efisiensi dan efektivitas, dan disusun dengan pendekatan kinerja. Penerapan kelima prinsip tersebut dalam prosesnya dipengaruhi oleh berbagai faktor, yaitu: SDM Aparatur, dokumen perencanaan (pembangunan dan penganggaran), daftar nominatif, anggaran, serta sarana dan prasarana. Adapun yang menjadi tujuannya adalah anggaran Diklatpim yang sesuai dengan kebutuhan SKPD Pengguna Anggaran.

2. Permasalahan atau kendala- kendala yang dihadapi dalam perencanaan anggaran Diklatpim pada Pemkab Mamuju, meliputi keterbatasan berbagai sumber daya yang dimiliki pemda (anggaran, SDM Aparatur, dan fasilitas diklat yang representatif), mekanisme pengiriman peserta berdasarkan kuota dan pemanggilan 
penyelenggara diklat, serta masih lemahnya komunikasi dan koordinasi diantara pihak- pihak berkepenttingan.

3. Untuk mengatasi berbagai masalah atau kendala tersebut, pihakpihak terkait telah melakukan berbagai upaya berikut: pengajuan telaahan staf penambahan anggaran kepada kepala daerah, perbaikan prosoes perencanaan anggaran dan penyelenggaraan kegiatan diklat, serta peningkatan intensitas komunikasi dan koordinasi di antara pihak-pihak berkepentingan.

\section{REKOMENDASI}

Untuk optimalisasi perencanaan anggaran yang disusun dan akselarasi perwujudan anggaran Diklatpim yang sesuai kebutuhan, penulis merekomendasikan atau menyarankan hal- hal berikut:

1. Rekomendasi Jangka Pendek, BKD Kabupaten Mamuju, selaku pengguna anggaran serta SKPD yang merumuskan dan melaksanakan kebijakan kepegawaian daerah, melakukan sosialisasi Diklatpim kepada berbagai pihak terkait di lingkungannya Pemkab Mamuju, khususnya kelompok sasaran kegiatan atau pejabat yang mengurusi masalah kepegawaian di unit kerja masing- masing ( misal: Kasubag/ Kasi Umum dan Kepegawaian). Bidang Diklat BKD Kabupaten Mamuju menyampaikan informasi secara berkala (semesteran atau tahunan) tentang hal- hal yang terkait dengan rencana anggaran dan kinerja Diklatpim kepada publik, terutama kelompok sasaran kegiatan. Selain melalui media konvensional yang digunakan selama ini, informasi tersebut juga disampaikan melalui media yang dapat menjangkau publik secara luas, misalnya situs ( website) resmi Pemkab dan BKD

2. Rekomendasi Jangka Menengah, Memberikan ruang yang cukup kepada publik, terutama PNSD atau Pejabat Struktural di Lingkungan Pemkab Mamuju selaku kelompok sasaran kegiatan, untuk mengetahui dan/ atau berpartisipasi dalam proses perencanaan anggaran Diklatpim. Misalnya, melalui pemanfaatan dan pengoptimalan kemajuan teknologi informasi berbasis elektronik. Pegawai atau pejabat struktural yang akan diikuti atau menjadi calon 
peserta Diklatpim diseleksi secara ketat terlebih dahulu oleh TSPDI, dimana pihak BKD menjadi salah satu unsur di dalam tim tersebut. Jadi, pencalonan dan penetapan calon peserta Diklatpim tidak hanya merujuk atau mendasarkan pada daftar nominatif pegawai. Komunikasi dan koordinasi yang telah dibangun BKD Kabupaten Mamuju dengan berbagai pihak internal dan ekstternal agar dapat terus dipelihara dan ditingkatkan intensitasnya. Upaya tersebut, misalnya, melalu forum pemangku kepentingan (stakeholders) yang diagendakan secara berkala.

3. Rekomendasi Jangka Panjang, Pemkab Mamuju melalui berbagai pihak terkait, seperti BKD, BAPPEDA, DPPKAD, dan TAPD, agar melakukan kajian lebih lanjut, baik legal, prosedural, maupun finansial, tentang opsi pengalihan pembebanan sebagai komponen biaya Diklatpim dari mata anggaran BKD ke unit kerja asal pegawai atau pejabat struktural yang diikutkan Diklatpim. Misalnya, biaya perjalanan dinas peserta dibebankan pada DPA/ DPPA- SKPD unit kerja asal peserta, sedangkan biaya kontribusi dan biaya penunjang kegiatan tetap dari DPA/ DPPA- SKPD BKD. Tim Badan Pertimbangan Jabatan dan Kepengankatan (BAPERJAKAT) hendaknya benar- benar menjadikan kelulusan Diklatpim sebagai salah satu dasar/ rujukan dalam pengembangan karir pegawai, baik mutasi maupun promosi. Sehingga kelompok sasaran kegiatan dapat melihat bahwa Diklatpim memang ada pengaruhnya terhadap jabatan (civil effect) pegawai dan tidak akan ada lagi penolakan dengan berbagai alasan pada saat dipanggil mengikuti Diklatpim yang menjadi salah satu penyebab tidak efektifnya anggaran Diklatpim yang direncanakan BKD.

\section{DAFTAR PUSTAKA}

Abu-Duhou Abtisam, School-Based Management (Manajemen Berbasis Sekolah), UNESCO, Penerjemah: Noryamin Aini, Suparto, 
Penyunting; Achmad Syahid, Abas Al-Jauhari, Jakarta: Logos, 2003

Allee, John Gage. Websters Dictionary. Chicago, Wilcox \& Folt Book Company, 2003.

Alwasilah, A, Chaedar, Pokoknya Kualitatif, Jakarta: Kiblat Buku Utama, 2003

Anselm Strauss \& Juliet Corbin, Dasar-dasar Penelitian Kualitatif, Tata langkah dan Teknik-teknik Teoritisasi Data, Penerjemah Muhammad Shodiq \& Imam Muttaqien, Yogyakarta: Pustaka Pelajar, 2003

Arifin, Anwar. Tinjauan tenteng Undang-undang Pendidikan. Jakarta: Departemen Pendidikan Nasional, 2009.

Arikunto, Suharsimi. Prosedur Penelitian suatu Pendekatan Praktek. Cet. XIII; Jakarta: PT Asdi Mahastya, 2006.

Arikunto, Suharsimi. Prosedur Penelitian; Suatu Pendekatan Praktek. Cet. IX; Jakarta: Renika cipta, 2003.

Brubacher, John S. Modern Philosophies of Education. New Delhi: Tata Graw-Hill Publishing Company LTD, 2001.

Chriswardani, Suryawati, Memahami Kemiskinan Secara Multidimensional, Jakarta : Bumi aksara, 2005

Departemen Pendidikan Nasional, Kamus Besar Bahasa Indonesia. Jakarta: Balai Pustaka, 2002.

Manajemen Peningkatan Mutu

Berbasis Sekolah Konsep Dasar, Jakarta : Ditjend Pendidikan Dasar dan Menengah, Ditjen SLTP. 2001

Edward dan Sallis, Manajemen Kualitas Total Dalam Pendidikan (Total Quality Management in Education penerjemah : Kambey Daniel C., Manado, Program Pasca Sarjana Universitas Negeri Manado, 2004 
., Undang-Undang Sistem Pendidikan Nasional, Nomor 20 Tahun 2003. Cet.II; Bandung: Fokusmedia, 2003.

UIN Aluddin, Pedoman Penulisan Karya Ilmiah; Makalah, Skripsi, Tesis, Disertasi, Edisi Revisi III. Makassar: UIN Alauddin, 2013.

Hadi, Sutrisno. Metodologi Research, jilid I. Cet. XX; Yogyakarta: Audi Ofsser, 2007.

Hamalik, Oemar. Evaluasi Kurikulum. Cet. II; Bandung : PT. Remaja Rosdakarya, 2003.

Hamid, Burhanuddin. Problematika Penyelenggaraan Pendidikan dengan Biaya Murah Bagi Peserta Didik Tingkat Sekolah Dasar di Kabupaten Sinjai "Tesis Magister". Makassar: Program Pascasarjana UMI, 2009.

Harnoto, Prof. Dr., Dinamika Pendidikan, Bandung, CV. Pustaka Setia, 1998.

Hasbullah, Sejarah Pendidikan Islam di Indonesia; Landasan Sejarah, Pertumbuhan dan Perkembangan. Jakarta: RajaGrafindo Persada, 2009.

H. A. Yunus, Drs., S.H., MBA. Filsafat Pendidikan, Bandung, CV. Citra Sarana Grafika. Bandung. 1999

Jarome S. Arcaro, pendidikan berbasisis mutu prinsip-prinsip perumusan dan tata langkah penerapan, Yogyakarta, Pustaka Pelajar, 2006.

K. Hitti, Philip. History of the Arabs. London Macmillan Press, 1970. Kambey Daniel C., Landasan Teori Administrasi / Manajemen ( Sebuah Intisari), Manado : Yayasan Tri Ganesha Nusantara, 2009

Kartini Kartono, Sistem Pendidikan Nasional, Jakarta: Pradnya Paramita, 2000.

, Pengantar Metodologi Riset Sosial, Bandung : Mandar Maju, 1990 
Keppel, G. Design \& Analysis: A Reseacher's Handbook. New Jersey : Prentice-Hall. 1982

Koran "Antara News", Anggaran Pendidikan di Mamuju terus Meningkat, selasa 20 Juli 2013.

., Pemerintah Kabupaten Mamuju Menyediakan Beasiswa bagi Siswa Berprestasi, selasa 22 Agustus 2013.

., Prestasi Siswa di Sejumlah Sekolah di Kabupaten Mamuju, Senin 21 Agustus 2013.

Mappanganro, Implementasi Pendidikan Islam di Sekolah. Cet.I; Ujung Pandang: Yayasan Ahkam, 2000.

Mardalis, Metode Penelitian. Cet. I; Jakarta: Bumi Aksara, 2000.

Mattulada, Sentralisasi Pendidikan dalam Manajemen Pembangunan. Jakarta: Pustaka Sinar Harapan, 2008.

Moleong, Lexy, J, Metodologi Penelitian Kualitatif, Bandung: Rosda Karya, 2001

Mudyahardjo, Redja. Pengantar Ilmu Pendidikan. Cet. II; Jakarta: PT. Raja Grafindo Persada, 2002.

Mulyasa E., Menjadi Kepala Sekolah Profesional, Bandung, PT Remaja Rosdakarya, 2005

Nawawi, Hadari. Organisasi Sekolah dan Pengelolaan Kelas. Cet. III; Jakarta: Haji Masagung, 2009.

Nazir, Moh. Metode Penelitian. Cet. III; Jakarta: Ghalia Indonesia, 2008.

Urkolis, 2003, Manajemen Berbasis Sekolah, Teori, Model dan Aplikasi, Jakarta : PT. Gramedia Widiasarana Indonesia, 2003.

Panglaykim dan Hazil Tanzil, Manajemen Suatu Pengantar. Cet. XV; Jakarta: Ghalia Indonesila, 2001.

Park, Joe. Selected Reading in The Philosophy of Education. New York: The Macmillang Companiy, 2000. 
Partanto, Pius A. dan M Dahlan al-Barry, Kamus llmiah Poputer. Surabaya: Arkola, 2004.

Pemerintah Daerah Kabupaten Mamuju, Peraturan Daerah (Perda) Nomor 10 Tahun 2008 tentang tentang Subsidi Biaya Pendidikan Pra Sekolah Pendidikan Dasar Dan Menengah. Mamuju: Dinas Pendidikan Nasional Kabupaten Mamuju, 2002.

Pidarta Made, 2004, Manajemen Pendidikan Indonesia, Jakarta: PT. Rineka Cipta. 1980

Pramusinto Purbokoso wibawa, Evaluasi Kebijakan Publik, Jakarta: Rajawali Press 2006

Rasidin K. Sitepu dan bonar M. Sinaga, Dampak Investasi Sumber Daya Manusia Terhadap Pertumbuhan Ekonomi dan Kemiskinan di Indonesia; pendekatan Model Computable General Equilibrium. Bandung : Alfabeta, 2004

Republik Indonesia, Kumpulan Peraturan Pemerintah RI dan Perundang-undangan, Instruksi Presiden dan Peraturan Lainnya. Bandung: Fokusmedia, 2009.

., Undang-Undang Nomor 22 Tahun 1999 tentang Pemerintah Daerah. Jakarta: CV. Novindo Pustaka Mandiri, 2000.

Rochaety Eti, Rahayuningsi Prima Gusti Yanti, Sistem Informasi Manajemen Pendidikan, Jakarta: Bumi Aksara, 2006

Pongtuluran, Aris. "Manajemen Mutu Total dalam Pendidikan", Makalah disampaikan dalam Konfrensi Nasional Manajemen Pendidikan, Jakarta: 2002.

Pramusinto Purbokoso wibawa, Evaluasi Kebijakan Publik, Jakarta: Rajawali Press, 2006

Salam, Burhanuddin. Pengantar Pedagogik; Dasar-dasar Ilmu Mendidik. Cet. I; Jakarta: Rineka Cipta, 2007. 
Senduk, J.E., Isu dan Kebijakan Pendidikan, Konsep dan Aplikasinya, Manado: Program Pasca Sarjana Universitas Negeri Manado, 2006

Soekarwati, monitoring dan evaluasi proyek pendidikan, Jakarta, dunia pustaka jaya, 1995.

Soebagio Admodiwirio, Manajemen Pendidikan Indonesia, Jakarta: Ardadijaya. 2000.

Sugiono, Metode Penelitian Kuantitatif, Kualitatif, dan R\&D, Bandung: Alfabeta, 2013

Sujana, Metode Statistik. Bandung: Tarsito, 2004.

Suryosubroto B., Manajemen Pendidikan di Sekolah, Jakarta: PT. Rineka Cipta. 2004.

Suparno Paul, dkk, Reformasi Pendidikan Sebuah Rekomendasi, Yogyakarta: Kanisius, 2002.

Sukardi, Metodologi Penelitian Pendidikan, Yogyakarta: Bumi Aksara, $200 \quad 3$

Syaharuddin, Konsep Profesionalisme Guru dalam Perspektif Pendidikan Islam; Studi Peningkatan Mutu Guru dan Pendidikan di MTs. Muhammadiyah Tallo Makassar, "Tesis Magister". Makassar: Program Pascasarjana UIN Alauddin Makassar, 2010.

Tampubolon, Daulat P. Perguruan Tinggi Bermutu: Paradigma Baru Manajemen Pendidikan Tinggi Menghadapi Abad ke-20. Cet. I; Jakarta: PT. Gramedia Pustaka Utama: 2001.

Tilaar, Prof. Dr., 2004, Manajemen Pendidikan Nasional, Bandung, PT. Remaja Rosdakarya, 2004

Tim Redaksi Fokusmedia, Undang-undang RI No. 20 Tahun 2003 tentang SISDIKDAS (sistem Pendidikan Nasional) 2003, Bandung: Fokusmedia 
Usman, Husaini, Metodologi Penelitian Sosial, Jakarta: Bumi Aksara, 2003.

Wasito, Herman. Pengantar Metodologi Penelitian. Jakarta: Gramedia Pustaka Utama, 2002.

Yamin, Martinas. Sertifikasi Profesi Guru di Indonesia Cet. I; Jakarta: Gaung Persada Press, 2006. 